J. Lake Sci. (湖泊科学), 2006, 18(2): 127-133

http:// www. jlakes. org. E-mail: jlakes@ niglas. ac.cn

(c) 2006 by Journal of Lake Sciences

\title{
鄱阳湖饶河段重金属污染水平与迁移特性”
}

\author{
简敏菲 ${ }^{1,2}$, 游 $^{\text {海 }^{1}}$, 倪才英 ${ }^{1}$
}

( 1 : 鄱阳湖生态环境与资源研究教育部重点实验室, 江西师范大学, 南昌 330022)

( 2 : 南昌大学环境科学与工程学院,南昌 330029 )

摘 要: 鄱阳湖饶河入湖段是鄱阳湖重金属污染最严重的水域之一, 为了研究其污染现状, 本文于 2005 年 3 月平水期对 鄱阳湖绕河段的水体、底泥、土壤及水生植物的重金属污染水平及迁移特性进行了调查与分析. 结果表明,饶河段水体中 的重金属除 $\mathrm{Pb}$ 的含量超出地表水环境质量标准 III 类标准外,其它各项监测指标均能达到地表水环境质量 III 类标准. 饶河 段底泥及河滩土壤的重金属含量平均值与国家土壤环境质量相比, $\mathrm{Zn} 、 \mathrm{Cd}$ 的平均值超出了三级标准, 而 $\mathrm{Cu} 、 \mathrm{~Pb}$ 的含量指 标均符合三级标准; 通过地质积累指数评价结果表明, 绕河段重金属底泥除 Zn 污染为中度污染以外,其他各种重金属污 染为轻度污染或偏中度污染, 且饶河段底泥中 $\mathrm{Cu} 、 \mathrm{Zn} 、 \mathrm{~Pb}$ 三种重金属元素之间呈极显著正相关. 饶河段水生植物对 $\mathrm{Cu} 、$ $\mathrm{Zn} 、 \mathrm{~Pb}$ 都有不同程度的富集; 根据富集系数评价表明, 植物对 $\mathrm{Cu}$ 的平均富集能力相对较强些, 其次是 $\mathrm{Pb}$ 和 $\mathrm{Zn}$, 多数水生 植物表现出对 Cd 具有一定的抗性.

关键词: 鄱阳湖;饶河段;底泥;水生植物;重金属污染;迁移转化

\section{Characteristics of heavy metals contaminant status and migration in Raohe River of Lake Poyang}

\author{
JIAN Minfei ${ }^{1,2}$, YOU Hai ${ }^{1} \&$ NI Caiying ${ }^{1}$ \\ (1:Key Lab. of Lake Poyang Ecological Environment and Resource Development, Jiangxi Normal University, Nan- \\ chang 330022 ,P. R. China) \\ (2: School of Environmental Science and Engineering, Nanchang University , Nanchang 330029,P. R. China. )
}

\begin{abstract}
The Raohe River at the intake of Lake Poyang, is one of the most seriously polluted areas in the Lake Poyang Basin. This paper was based on a survey of heavy metal concentration and migration characteristics in water, sediment, soil, and aquatic plants from this area in March, 2005. The results indicate that the content of the heavy metals $\mathrm{Cu}, \mathrm{Zn}$ and $\mathrm{Cd}$ in the water in the investigated areas meet class III criterion for surface water evalution. $\mathrm{Pb}$, however, did not meet this criterion. The average concentration of $\mathrm{Zn}$ and $\mathrm{Cd}$ in sediment and soil in the sampling sites did not meet class III criterion for soil evaluation, but the average sediment and soil concentration of $\mathrm{Cu}$ and $\mathrm{Pb}$ did meet. The index of geography accumulation results indicate that zinc contamination has reached a moderately advanced stage of pollution, and the other metals such as $\mathrm{Cu}, \mathrm{Pb}$, and $\mathrm{Cd}$ only superficially pollute the sediment. The three heavy metals $\mathrm{Cu}, \mathrm{Zn}$, and $\mathrm{Pb}$ in sediment and soil show a positive correlation. Different kinds of aquatic plants in the sampling sites had different enrichment by the different heavy metals $\mathrm{Cu}, \mathrm{Zn}$, and $\mathrm{Pb}$. According to the assessment of enrichment coefficient, the average enrichment coefficient of $\mathrm{Cu}$ contamination in aquatic plants was relatively higher than $\mathrm{Pb}$ and $\mathrm{Zn}$. Most aquatic plants in Raohe River of Lake Poyang resisted contamination by Cd.
\end{abstract}

Keywords : Lake Poyang; Raohe River;sediment; aquatic plants; heavy metals pollution, removal and transfer

* 鄱阳湖生态环境与资源研究教育部重点实验室开放基金项目 (PK2004008) 和江西省教育厅科技项目 (20021203) 联合资助. $2005-05-08$ 收稿; $2005-08-08$ 收修改稿.

简敏菲,女,1969 年生,在读博士, 副教授;E-mail : jianminfei0914@ 163. com. 
鄱阳湖是中国最大的淡水湖,也是国际最重要的湿地之一, 并具有复杂的生物多样性及丰富的生态资 源. 鄱阳湖五大水系之一的饶河受其流域乐安河中上游德兴铜矿的开采及其它重工业污染以及非点源污染 的影响,其水土环境受到了各种不同程度的污染, 尤其以重金属元素 $\mathrm{Cu} 、 \mathrm{Zn} 、 \mathrm{~Pb} 、 \mathrm{Cd}$ 的污染问题较为突出, 对饶河流域及鄱阳湖局部区域的农村生态环境造成了重要影响 ${ }^{[1]}$. 由于重金属元素具有难降解、易积累、 毒性大的特性, 对于作物的生长、产量、品质均有较大的危害, 尤其是还具有被生物富集吸收、进人食物链、 从而危害人、畜、鸟类等生命健康的潜在危险, 调查研究鄱阳湖湿地重金属污染物的迁移转化规律具有十分 重要的意义.

鄱阳湖湿地的许多水生植物、水生动物都是重要的生物资源, 具有许多重要的利用价值和食用价值: 许 多水生植物可作饵料、饲料、食物、蔬菜、药材、肥料、编织及造纸原料; 用作净化水质和指示水质的污染程 度, 以水生植物作为研究对象能从一定程度上反映鄱阳湖湿地重金属迁移转化的规律及分布特点. 研究鄱 阳湖湿地重金属污染物的迁移转化有利于预测鄱阳湖湿地重金属污染的演化趋势,有利于加强保护鄱阳湖 湿地的生态平衡, 并充分发挥湿地保护水体的功能, 为制定鄱阳湖的水质保护规划提供重要的科学依据和 学术价值.

\section{1 样品采集和实验方法}

\section{1 样品来源及监测指标}

本文研究的样品是 2005 年 3 月平水期采自鄱阳湖饶河入湖段——鄱阳县饶河口的电排站、红旗村等 重金属污染的典型区域,同时以未受污染的南矶山自然保护区作为对照点 (图 1). 样品主要为各采样点的 水样、底泥、土壤、水生植物等, 监测指标主要有各样品中的 $\mathrm{Cu} 、 \mathrm{Zn} 、 \mathrm{~Pb} 、 \mathrm{Cd}$ 等, 辅助调查项目有水样 $\mathrm{pH}$ 值、 底泥、土壤的 $\mathrm{pH}$ 值、含水率、湿密度、水深、水温等.

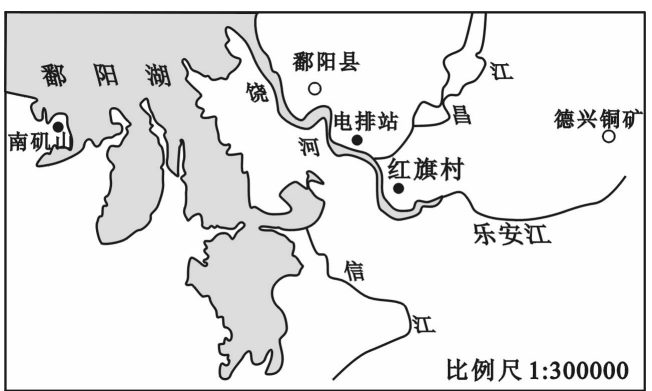

图 1 鄱阳湖饶河入湖段采样点布设图

Fig. 1 Sampling sites in Raohe River of Lake Poyang

\section{2 样品前处理}

1.2 .1 底泥或土壤样品的前处理 现场采得底泥或土 壤样品, 用封口的聚乙烯塑料袋装好带回实验室后, 经 自然风干、除杂、混合均匀后, 再用烘箱烘干, 用碾钵将 样品研磨过 100 目尼龙篎, 用四分法进行缩分, 从中取 出 $500-1000 \mathrm{~g}$ 样品, 分装在用硝酸处理过的广口聚乙 烯塑料瓶中, 并加人浓硝酸酸化, 使 $\mathrm{pH}$ 达到 3.5 以防 止重金属离子的沉淀或吸附于容器表面而导致损失, 处理后可长期低温保存.

土壤样品的分解方法采用全分解方法 ${ }^{[2]}$, 用 WMX 型微波炉、聚四氟乙烯消解罐溶样法消解, 准确称取 $0.1000 \mathrm{~g}$ 土样,采用 $2 \mathrm{ml}$ 浓硝酸、5 $\mathrm{ml}$ 浓氢氟酸、 $5 \mathrm{ml}$ 高 氯酸、 $2 \mathrm{ml}$ 浓盐酸形成混合消解体系,加盖密封后置于

微波炉中在 1.5 MPa 恒压下, 按程序 100\% 功率消解, 消解时间一般为 6-10min 即可, 消解后的样品经冷 却、定容至 $50 \mathrm{ml}$ 后过滤备用，按水样重金属的标准方法测定 ${ }^{[3]}$.

1.2.2 水生植物样品的前处理 带回实验室的植物样品, 用自来水将其表面的泥土冲洗干净, 再用超纯蒸 馏水漂洗, 晾干后用不锈钢刀切碎, 取全株进行分析, 植物湿样放人 $105^{\circ} \mathrm{C}$ 电热干燥箱中烘至恒重干样 (大 约 $5 \mathrm{~h}$ 以上). 植物干样用植物粉碎机粉碎后, 用四分法逐步缩分得待测植物样, 装人硝酸处理过的聚乙烯 塑料袋或广口聚乙烯塑料瓶中, 放人干燥器中保存备用.

植物样品消解也采用微波炉、聚四氟乙烯消解罐全分解法消解处理. 准确称取 $0.5000 \mathrm{~g}$ 植物干样置于 聚四氟乙烯消解罐中, 用 $2 \mathrm{ml}$ 超纯蒸馏水湿润, 加人 $70 \%$ 优级纯浓 $\mathrm{HNO}_{3} 10 \mathrm{ml}$, 混匀后, 将消解罐加盖密封 好, 置于微波炉中, 压力调至 $1.5 \mathrm{Mpa}$, 按程序 $100 \%$ 功率消解, 消解时间一般为 6-10 min 即可, 消解后的样 品经冷却, 加人 $1 \mathrm{ml} 1+1 \mathrm{HCl}$ 溶液, 将样品中的无机盐全部溶解, 溶解液移人 $50 \mathrm{ml}$ 容量瓶中, 用超纯蒸馏水 少量多次地润洗消解罐, 定容至刻度,混匀后过滤备用,按水样中重金属的标准方法测定,同时做试剂空白 
试验.

\section{3 仪器、试剂与测定方法}

3510 型原子吸收分光光度计 (安捷伦科技 (上海) 有限公司生产)、WMX 型微波炉 (广东汕头仪器制造

厂)、聚四氟乙烯消解罐、雷兹 PXS-215 型离子型酸度计.

水样与土样 $\mathrm{pH}$ 值的测定采用雷兹 PXS-215 型离子酸度计测定; 重金属元素含量采用 3510 型原子吸收 分光光度计测定,水样中 $\mathrm{Cu} 、 \mathrm{Zn} 、 \mathrm{~Pb} 、 \mathrm{Cd}$ 等重金属元素总量的测定采用国家环境保护局 1987-03-14 批准的 标准方法进行测定 ${ }^{[4]}$, 水样中重金属的含量均以 $\mathrm{mg} / \mathrm{L}$ 计; 土样及植物中的重金属测定采用国家标准方 法 $^{[5]}$,土样及植物样品中的重金属含量均为样品的干基含量 (以 $\mathrm{mg} / \mathrm{kg}$ 计).

药品浓硝酸、高氯酸、氢氟酸均为优级纯, 浓盐酸为分析纯.

\section{2 结果与讨论}

\section{1 水体的重金属污染评价}

对采样点水样进行性状分析, 水样外观稍呈浑浊, 现场测定 $\mathrm{pH}$ 值, 水样经硝酸固定后带回实验室消解 处理并过滤后进行重金属含量测定,测定结果及地表水环境质量三类标准如表 1 所示.

表 1 不同采样点水样 $\mathrm{pH}$ 值及重金属元素含量

Tab. 1 Contents of heavy metals in water of different sampling sites

\begin{tabular}{ccccccc}
\hline 编号 & 采样点 & $\mathrm{Cu}(\mathrm{mg} / \mathrm{L})$ & $\mathrm{Pb}(\mathrm{mg} / \mathrm{L})$ & $\mathrm{Zn}(\mathrm{mg} / \mathrm{L})$ & $\mathrm{Cd}(\mathrm{mg} / \mathrm{L})$ & $\mathrm{pH}$ 值 \\
\hline $\mathrm{W} 1$ & 饶河红旗村 & 0.062 & 0.027 & 0.01 & 未检出 & 7.30 \\
$\mathrm{~W} 2$ & 饶河红旗村中垂线 & 0.050 & 0.023 & 未检出 & 未检出 & 7.32 \\
$\mathrm{~W} 3$ & 饶河电排总站中垂线 & 0.047 & 0.021 & 未检出 & 未检出 & 7.40 \\
W4 & 南矶山自然保护区 & 0.042 & 0.020 & 未检出 & 未检出 & 7.45 \\
& 地表水环境质量标准 & 1.0 & 0.01 & 1.0 & 0.005 & $6-9$ \\
& (GB 3838-2002, 而类) & & & & & \\
\hline
\end{tabular}

上表结果显示,各样点水体中的重金属含量相对都较低,除 $\mathrm{Pb}$ 的含量超出地表水环境质量标准 III类标 准外, 其它各项监测指标及 $\mathrm{pH}$ 值均能达到地表水环境质量 III 类标准, 且多数样点中均未检出 $\mathrm{Zn} 、 \mathrm{Cd}$ 的含 量. 水体中 $\mathrm{Pb}$ 含量超出地表水的 III 类标准而低于地表水的 $\mathrm{IV}$ 类标准, 由于饶河水体直接由饶河口经由龙口 汇人鄱阳湖,在一定程度上造成鄱阳湖重金属污染的直接隐患, 因此,对饶河水体中的重金属污染应引起足 够的重视.

表 2 不同采样点底泥或土壤重金属含量、pH 值与标准值的对照

Tab. 2 Comparison of heavy metals contents in the sediment and soil of Raohe River with different standard

\begin{tabular}{|c|c|c|c|c|c|c|}
\hline 编号 & 采样点 & $\mathrm{Cu}(\mathrm{mg} / \mathrm{kg})$ & $\mathrm{Pb}(\mathrm{mg} / \mathrm{kg})$ & $\mathrm{Zn}(\mathrm{mg} / \mathrm{kg})$ & $\mathrm{Cd}(\mathrm{mg} / \mathrm{kg})$ & $\mathrm{pH}$ 值 \\
\hline $\mathrm{S} 1-1$ & 红旗村饶河底泥 & 96.65 & 160.52 & 1029.8 & 1.23 & 6.4 \\
\hline $\mathrm{S} 1-2$ & 红旗村饶河河滩土壤 & 98.00 & 163.03 & 1036.8 & 2.28 & 5.44 \\
\hline $\mathrm{S} 2-1$ & 电排总站饶河底泥 & 84.25 & 133.51 & 1014.5 & 0.87 & 6.94 \\
\hline $\mathrm{S} 2-2$ & 电排总站饶河河滩土壤 & 74.00 & 109.00 & 1014.5 & 1.01 & 8.47 \\
\hline $\mathrm{S} 3-1$ & 南矶山常湖底泥 & 66.02 & 105.46 & 724.45 & 未检出 & 7.36 \\
\hline \multirow[t]{3}{*}{$\mathrm{S} 3-2$} & 南矶山常湖草滩土壤 & 79.39 & 106.94 & 872.33 & 未检出 & 6.38 \\
\hline & $\begin{array}{c}\text { 土壤环境质量标准 } \\
\text { ( GB 15618-1995, 三级) }\end{array}$ & 400.0 & 500.0 & 500.00 & 1.00 & $6.5-7.5$ \\
\hline & 鄱阳湖流域底泥背景值 ${ }^{[6]}$ & 6] 4.75 & 12.50 & 45.75 & 0.75 & \\
\hline
\end{tabular}




\section{2 底泥重金属污染的特性}

2.2.1 底泥的基本性状 饶河入湖段相应样点采得的表层底泥样 $(0-20 \mathrm{~cm})$ 呈黑褐色,泥质松软、均匀,易 变形,不含植物根、叶残骸. 取表层底泥分析, 饶河底泥新鲜底泥含水率 $63.54 \%-78.23 \%$,湿密度 $1.54-$ $1.85 \mathrm{~g} / \mathrm{cm}^{2}$, 性状分类上属于粉质粘土.

2.2 .2 重金属的污染特性 土壤或底泥中的 $\mathrm{pH}$ 值对重金属的迁移转化有一定的影响, 表 2 列出了饶河人 湖段与对照点南矶山各样点底泥、土壤重金属含量的平均值及 $\mathrm{pH}$ 值的测定结果.

从上表可以分析, 与国家土壤环境质量相比,样点底泥或土壤中的 $\mathrm{Zn} 、 \mathrm{Cd}$ 平均值超出了三级标准, 而 $\mathrm{Cu} 、 \mathrm{~Pb}$ 的含量指标均符合三级标准. 与鄱阳湖流域底泥背景值 ${ }^{[6]}$ 相比,所测 4 种重金属元素的平均值分别 超过背景值的 1.4 倍 $(\mathrm{Cd})$ 到 22.34 倍 $(\mathrm{Zn})$. 根据超出背景值的倍数分析, 得出饶河底泥重金属含量顺序为 $\mathrm{Zn}(22.34)>\mathrm{Cu}(19.04)>\mathrm{Pb}(11.76)>\mathrm{Cd}(1.40)$.

从表中还可以分析, 样点底泥或土壤中 $\mathrm{pH}$ 值比较接近于中性, 且各种重金属元素的含量与其 $\mathrm{pH}$ 值具 有一定的相关性,一般情况是 $\mathrm{pH}$ 值越低,重金属元素的总量越高,这可能与土壤 $\mathrm{pH}$ 值影响重金属的形态 分布有一定的关联,从而影响重金属的总量分布,这与有关文献的报道 ${ }^{[7,8]}$ 也比较吻合.

水体底泥中的重金属含量可作为一个判断标准,用来说明水体中重金属污染物的循环特征. 目前常用 的重金属污染评价方法有重金属污染指标 MPI( Metal pollution index) 法 ${ }^{[9]}$ 、均方根综合污染指数法、地积累 指数法 ${ }^{[10]}$,脸谱图法 ${ }^{[11]}$ 等等.

地积累指数法是德国海德堡大学沉积特性研究所的 Muller ${ }^{[12]}$ 教授提出的, 是一种研究水环境沉积中 重金属污染的定量指标 ${ }^{[13]}$, 计算公式如下:

$$
I_{\text {geo }}=\log _{2} C_{n} /\left(K \cdot B_{n}\right)
$$

式中, $C_{\mathrm{n}}$ 为实测重金属浓度, $\mathrm{mg} / \mathrm{kg}, B_{\mathrm{n}}$ 为普通页岩中重金属地球化学平均背景值, 其中 $\mathrm{Cu}: 45.0 ; \mathrm{Pb}: 34.0$; $\mathrm{Zn}: 97.0 ; \mathrm{Cd}: 0.40 ; K$ 为考虑到造岩运动可能引起背景值波动而设定的常数, $K=1.5$.

将沉积物中重金属污染状况划分为 7 个等级 (表 3 ); 根据地积累指数法计算公式,将样品重金属污染 的实测结果转换为 $I_{\mathrm{geo}}$ 和污染分级 (表 4 ).

表 3 重金属污染级别与 $I_{\text {geo }}$ 比较

Tab. 3 Comparison of pollution level of heavy metals and $I_{\text {geo }}$

\begin{tabular}{cccccccc}
\hline \multicolumn{7}{c}{ 污染指标 } \\
\hline$I_{\text {geo }}$ & $\leqslant 0$ & $>0-\leqslant 1$ & $>1-\leqslant 2$ & $>2-\leqslant 3$ & $>3-\leqslant 4$ & $>4-\leqslant 5$ & $>5$ \\
污染级别 & 清洁 & 轻度污染 & 偏中度污染 & 中度污染 & 偏重度污染 & 重度污染 & 严重污染 \\
\hline
\end{tabular}

表 4 饶河底泥重金属污染元素的地积累指数及其分级

Tab. $4 I_{\text {geo }}$ and rank of heavy metal pollution in sediments of Raohe River

\begin{tabular}{|c|c|c|c|c|}
\hline 项目 & $\mathrm{Cu}$ & $\mathrm{Pb}$ & $\mathrm{Zn}$ & $\mathrm{Cd}$ \\
\hline 地球化学平均背景值 $(\mathrm{mg} / \mathrm{kg})$ & 45.0 & 34.0 & 97.0 & 0.40 \\
\hline 饶河红旗村底泥中的测定值 (mg/kg) & 96.65 & 160.5 & 1029.8 & 1.233 \\
\hline$I_{\text {geo }}$ & 0.518 & 1.654 & 2.823 & 1.039 \\
\hline 污染程度 & 轻度污染 & 偏中度污染 & 中度污染 & 偏中度污染 \\
\hline 饶河电排总站底泥中的测定值 $(\mathrm{mg} / \mathrm{kg})$ & 84.25 & 133.5 & 1014.5 & 0.865 \\
\hline$I_{\text {geo }}$ & 0.320 & 1.388 & 2.802 & 0.528 \\
\hline 污染程度 & 轻度污染 偏中度污染 & 中度污染 & 轻度污染 & \\
\hline
\end{tabular}

从上表数据可以看出, 鄱阳湖饶河段两个不同点的重金属污染程度各不相同,其中 $\mathrm{Cu}$ 为轻度污染, $\mathrm{Pb}$ 为偏中度污染, $\mathrm{Zn}$ 为中度污染. 总体上看, 红旗村的污染程度略高于电排总站的污染程度. 
对饶河段底泥中 4 种重金属元素的相关性进行 线性回归分析,计算各种重金属元素之间的相 关系数,相关系数反映了各种元素之间的复合 污染问题. 分析结果见表 5 , 表 5 中 $\mathrm{Cu}$ 与 $\mathrm{Zn} 、 \mathrm{Cu}$ 与 $\mathrm{Pb} 、 \mathrm{Zn}$ 与 $\mathrm{Pb}$ 之间都呈显著水平 $1 \%$ 的正相 关, 即 $\mathrm{Cu} 、 \mathrm{Zn} 、 \mathrm{~Pb}$ 三种元素之间呈显著正相关, 因此在鄱阳湖湿地几个相关的采样点出现了几 种重金属元素含量同时增高的现象,呈现复合 污染的趋势. 而 $\mathrm{Cd}$ 与其它元素之间的相关性 则较小, 达不到显著相关的水平.

\section{3 水生植物富集重金属污染物的特性}

本文采得的水生植物样品主要为采样点河滩上的一年生草本植物, 平水期采得植物均为处于生长初期 的嫩芽植物. 采样点河滩上分布的的主要植物群落有狗牙根 + 紫云英 + 牛筋草 + 水芹 + 苔草 + 羊蹄 + 黄花 蒿等, 沙洲上分布有大片的羊蹄 + 水芹 + 紫云英等草本植物, 对各种水生植物作重金属含量分析, 测定结果 如表 6 所示.

表 6 不同采样点水生植物中各种重金属元素含量 $(\mathrm{mg} / \mathrm{kg})$

Tab. 6 Concentration of eavy metals in different aquatic plants in different sampling sites

\begin{tabular}{|c|c|c|c|c|c|c|}
\hline 采样点 & 植物名称 & 学名 & $\mathrm{Cu}$ & $\mathrm{Zn}$ & $\mathrm{Pb}$ & $\mathrm{Cd}$ \\
\hline \multirow[t]{11}{*}{ 红旗村饶河河滩 } & 紫云英 & Astragalus sinicus $\mathrm{L}$. & 32.58 & 128.94 & 15.42 & 未检出 \\
\hline & 狗芽根 & Cynodcon dactyvon ( L. ) Pors. & 46.91 & 136.98 & 46.21 & 未检出 \\
\hline & 水芹 & Oenanthe L. & 28.51 & 118.99 & 21.73 & 0.304 \\
\hline & 羊蹄 & Rumes japonicus & 16.05 & 107.17 & 16.85 & 未检出 \\
\hline & 马齿苋 & Portulaca oleracea $\mathrm{L}$. & 31.56 & 187.18 & 41.12 & 未检出 \\
\hline & 荠菜 & Capsellae bursa - pastori & 15.41 & 146.08 & 16.75 & 未检出 \\
\hline & 牛筋草 & Eleusine indica ( L. ) Gaertn. & 23.33 & 122.59 & 14.88 & 未检出 \\
\hline & 一年蓬 & Erigeron annuus (L. ) pers. & 26.32 & 137.59 & 25.17 & 0.773 \\
\hline & 黄花蒿 & Artemisia аппиа $\mathrm{L}$. & 17.86 & 114.47 & 15.42 & 未检出 \\
\hline & 苔草 & C. leucochlora Bunge & 28.50 & 157.40 & 25.64 & 未检出 \\
\hline & 车前 & P. asiatica $\mathrm{L}$. & 15.62 & 102.40 & 8.084 & 未检出 \\
\hline \multirow[t]{7}{*}{ 电排总站饶河河滩 } & 紫云英 & Astragalus sinicus $\mathrm{L}$. & 15.35 & 110.45 & 24.25 & 未检出 \\
\hline & 一年蓬 & Erigeron annuиs (L. ) pers. & 14.22 & 120.80 & 20.81 & 未检出 \\
\hline & 水芹 & Oenanthe L. & 8.33 & 99.80 & 21.31 & 未检出 \\
\hline & 羊蹄 & Rumes japonicus & 20.14 & 118.18 & 18.63 & 未检出 \\
\hline & 泥胡菜 & Hemistepta lyrata Bunge & 13.00 & 102.75 & 12.50 & 未检出 \\
\hline & 鸡眼草 & Kumerowia soriata Schindl & 9.29 & 106.49 & 20.83 & 未检出 \\
\hline & 旱芹 & Apium graveolensl. var. dulce DC & 18.86 & 119.12 & 17.86 & 未检出 \\
\hline \multirow{3}{*}{ 对照样点: 南矶山 } & | 艾蒿 & Artemisia L. & 5.53 & 105.46 & 12.66 & 未检出 \\
\hline & 大马蓼 & Polygonum lapathifolium $\mathrm{L}$. & 11.90 & 62.15 & 15.86 & 未检出 \\
\hline & 苔草 & C. leucochlora Bunge & 16.29 & 61.10 & 12.72 & 未检出 \\
\hline
\end{tabular}

上表结果显示,各样点不同植物对 $\mathrm{Cu} 、 \mathrm{Zn} 、 \mathrm{~Pb}$ 都有不同程度的吸收与富集,而且植物对重金属元素的 富集与环境背景值的含量具有一定的相关性, 以饶河河滩土壤为例, 由于环境中 Zn 的含量较高, 各种植物 对锌的富集也表现出较高的含量; 同时,各种植物对 $\mathrm{Cu} 、 \mathrm{~Pb}$ 均表现出一定的吸收与富集,但富集含量相对 
较低些; 多数植物体内未能检出 $\mathrm{Cd}$ 含量, 只有个别植物中检出了 $\mathrm{Cd}$, 表现出多数植物对 $\mathrm{Cd}$ 的吸收或富集 具有一定的排斥性. 从上表还可看出, 红旗村饶河河滩大多数植物中的重金属含量要高于电排总站饶河河 滩和南矶山, 这表明植物吸收富集重金属元素与土壤背景值呈正相关, 土壤背景含量越高, 植物吸收得越 多,表现出重金属从土壤(底泥) 向植物迁移的主要特征.

植物对重金属元素的富集与植物种类、植物生态习性以及环境因素等密切相关,因此不同样点相同植 物或者同一样点不同植物对重金属元素的富集都存在一定的差异. 为了反映不同植物在不同环境中对不同 重金属元素的富集能力,本文采用富集系数 $\left(K_{i}\right)$ 进行定量评价,富集系数的计算公式为:

$$
K=\frac{C_{o i}}{C_{e i}}
$$

式中: $C_{o i}$ 为受检植物体内某种重金属元素的残留量 $(\mathrm{mg} / \mathrm{kg}) ; C_{e i}$ 为受检植物所在环境中重金属的实测浓度 $(\mathrm{mg} / \mathrm{kg})$.

$K$ 值大小表明受检植物对环境中重金属的富集能力. 根据各种植物中的残留量及土壤环境中的实测 值, 计算不同样点、不同植物对重金属元素的富集系数, 并将电排总站样点采得的不同植物中的各种重金属 元素的富集系数进行分析比较 (图 2); 不同样点同一植物各种重金属元素的富集系数的柱状分析结果见 图 3.

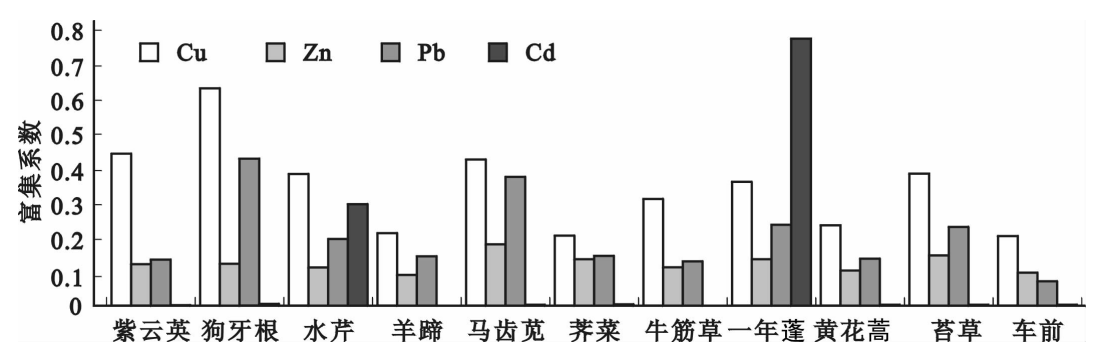

图 2 同一采样点不同植物对重金属元素富集系数的比较

Fig. 2 Coeffiecient of different plants in the same sampling sites

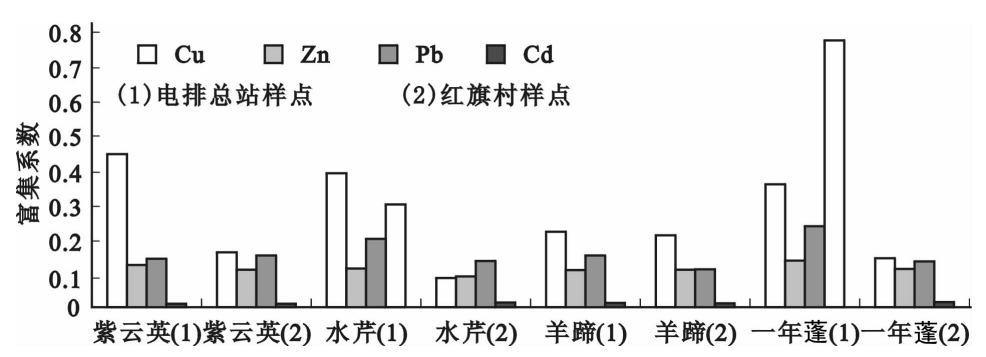

图 3 不同采样点同种植物富集系数的比较

Fig. 3 Coeffiecient of the same plant in different sampling sites

通过以上分析可直观地比较, 饶河人湖段重金属元素在不同植物中的迁移转化具有不同的特性. 一方 面, 同一样点不同植物对不同重金属元素的富集具有一定的选择性和差异性,一般植物对 $\mathrm{Cu}$ 的富集能力相 对较强些, 其次是 $\mathrm{Pb}$ 和 $\mathrm{Zn}$, 而绝大多数植物对 $\mathrm{Cd}$ 的富集能力普遍较弱, 表现出植物对 $\mathrm{Cd}$ 具有较强的抗 性; 另一方面,不同样点同一植物的富集也存在一定的差异性,表现出植物的富集与环境背景值之间存在一 定的正相关性. 


\section{4 结论}

通过对鄱阳湖饶河人湖段水体、底泥、土壤及植物等不同要素中重金属含量的调查与分析评价,表明重 金属污染物在不同样点、不同环境要素中具有一定的迁移转化特性.

饶河段水体中重金属含量除 $\mathrm{Pb}$ 的含量超出地表水环境质量标准 III 类标准外, 其它各项监测指标及 $\mathrm{pH}$ 值均能达到地表水环境质量 III类标准, 且各样点的 Zn、Cd 均未检出, 表现出重金属元素在水体中具有难溶 解、易沉积、易吸附的特性.

各样点底泥及河滩土壤中的重金属含量远远高于水体中的含量, 且不同元素呈现出极显著正相关性, 出现了 $\mathrm{Cu} 、 \mathrm{Zn} 、 \mathrm{~Pb}$ 几种重金属元素含量同时增高的现象, 即呈现出复合污染的趋势. 且底泥中各种重金属 元素的含量与其 $\mathrm{pH}$ 值具有一定的相关性, $\mathrm{pH}$ 值越低, 重金属元素的含量越高.

各样点水生植物对重金属元素 $\mathrm{Cu} 、 \mathrm{Zn} 、 \mathrm{~Pb}$ 有不同程度的富集; 且各种植物富集重金属元素的能力存在 一定差异和选择性, 植物对 $\mathrm{Cu}$ 的富集能力相对较强些, 其次是 $\mathrm{Pb}$ 和 $\mathrm{Zn}$, 大多数植物体中未能检出 $\mathrm{Cd}$ 的含 量, 只有个别植物中检出 $\mathrm{Cd}$ 含量, 表现出植物对 $\mathrm{Cd}$ 具有一定的抗性. 植物对重金属元素的吸收、富集与植 物的种类及植物的生态习性、土壤的 $\mathrm{pH}$ 值等理化特性及其它环境因素都有密切关系.

在饶河人湖段不同样点,各种环境要素中的重金属污染呈现出一定的演化规律,随着样点对污染源的 远离, 各种重金属元素的含量呈现出衰减的趋势, 反映了重金属污染物在随着水体的流动而沉降削减.

致谢: 江西师范大学地理与环境学院人文地理学硕士研究生刘厚仙、宋玉斌参与了课题野外采样与实验室 分析; 美国密西根大学硕士研究生 CARRIE. KNOWLTON 在江西师范大学地理与环境学院留学期间参与了 本课题的野外采样与实验, 在此一并表示感谢!

\section{5 参考文献:}

[1] 简敏菲, 弓晓峰,游 海等. 鄱阳湖水土地理环境及其水生维管束植物重金属污染. 长江流域资源与 环境, 2004,13(6):589-593.

[2] 中国环境监测总站编著.土壤元素的近代分析方法. 北京: 中国环境科学出版社, 1992:64-73.

[3] 水和废水监测分析方法. 国家环保总《水和废水监测分析方法》编委会编. 第 4 版. 北京: 中国环境科 学出版社, 2002 .

[4] 中国标准出版社第二编辑室编. 水质分析方法国家标准汇编. 北京: 中国标准出版社,1996:49-55.

[5] 李泽琴,程温芗,罗 丽等. 成都市某蔬菜基地重金属污染状况分析. 地质灾害与环境保护,2002,13 (4) $: 24-27$.

[6] 鄱阳湖研究编委会. 鄱阳湖研究. 上海: 上海科学技术出版社, 1988 .

[7] 夏增禄. 中国若干土壤类型剖面中元素的自然含量特征及其相互关系. 中国科学 (B), 1985, (7)：658 $-667$.

[8] 罗金发,孟维奇,夏增禄.土壤重金属 (镉、铅、铜)化学形态的地理分异研究. 地理研究, 1998,17(3): $265-272$.

[9] 黄 亮, 李 伟, 吴 莹等. 长江中游若干湖泊中水生植物体内重金属分布. 环境科学研究, 2002,15 (6) $: 1-4$.

[10] 戴秀丽,孙 成.太湖沉积物中重金属污染状况及分布特征探讨.上海环境科学,2001,20(2):71-75.

[11] 方开泰. 实用多元统计分析.上海:华东师范大学出版社. 1989:257-288.

[12] Muller G. Sediment Index. Chemiker Zeitung, 1981,105:53 - 58 .

[13] 沈亦龙,何品晶, 邵立明. 太湖五里湖底泥污染特性研究. 长江流域资源与环境, 2004,13(6), 584 -588 . 